Gut, 1976, 17, 345-350

\title{
Hypothalamic-pituitary-gonadal function in men with cirrhosis of the liver
}

\author{
N. A. G. MOWAT*, C. R. W. EDWARDS, R. FISHER, A. S. MCNEILly, J. R. B. \\ GREEN, AND A. M. DAWSON \\ From the Departments of Gastroenterology, Medicine, and Chemical Pathology, St. Bartholomew's \\ Hospital, London
}

SUMMARY Hypothalamic-pituitary-gonadal function was studied in 37 cirrhotic males, 25 of whom were alcoholic. Irrespective of aetiology, cirrhotic patients had significantly reduced free testosterone concentrations. Despite low free testosterone concentrations and reduced or absent spermatogenesis, basal levels of luteinizing hormone (LH) and follicle stimulating hormone (FSH) were normal in nearly all patients, suggesting impaired function of the hypothalamic-pituitary-gonadal axis. In 14 cirrhotic men, seven of whom had gynaecomastia, the ability of the pituitary to secrete LH and FSH in response to exogenous gonadotrophin releasing-hormone (LH/FSH-RH) was assessed. A normal LH response to LH/FSH-RH was obtained in patients without gynaecomastia. An exaggerated LH response was found in four of seven with gynaecomastia, suggesting Leydig cell failure. The Leydig cell response to exogenous gonadotrophin in eight consecutive cirrhotic patients was probably abnormal but difficult to interpret as all but one were within conventionally accepted limits of normality. The patients without gynaecomastia gave a normal or minimally exaggerated FSH response to LH/FSH-RH. Six of seven with gynaecomastia gave a markedly exaggerated response suggesting failure of spermatogenesis, and all tested were either azoospermic or oligospermic. The single patient with a normal FSH response had a normal sperm count. The pituitary cells can therefore respond to LH/FSH-RH and the Leydig cells of the testes show some response to exogenous gonadotrophin. Similar abnormalities in hypothalamic-pituitary-gonadal function have recently been described in patients with normal liver function on chronic oestrogen therapy.

Loss of the normal male secondary sex characteristics is common in patients with chronic liver disease (Corda, 1925; Glass et al., 1940; Lloyd and Williams, 1948; Summerskill et al., 1960). Traditionally these clinical signs have been attributed to hormonal imbalance secondary to chronic liver disease, but recently it has been postulated that alcohol may have a specific action quite independent of its hepatotoxic effect (van Thiel and Lester, 1974). Despite the advent of specific radioimmunoassays a universally acceptable hormonal basis for clinical features such as gynaecomastia and testicular atrophy has not been established (Adlercreutz, 1970; 1974). In particular, the role of oestrogens remains in dispute. While some authors have reported ele-

*Present address: Department of Gastroenterology, Woodend General Hospital, Aberdeen.

Received for publication 12 Fcbruary 1976 vated oestradiol levels (Korenman et al., 1969; Cedard et al., 1970; Lourens, 1973; Chopra et al., 1973), others have found these to be normal (GalvãoTeles et al., 1973; Kent et al., 1973). Disturbed androgen metabolism has also been reported. Earlier reports (Coppage and Cooner, 1965; Baker et al., 1972; Vermeulen et al., 1972a; Lourens, 1973) suggested low or normal testosterone levels, but Galvão-Teles et al. (1973) found a significant fall in the unbound biologically active androgens (measured as $17 \beta$-hydroxyandrogens) associated with a significant rise in sex hormone binding globulin (SHBG) concentrations.

To confirm and extend these studies, a larger group of patients including alcoholic and nonalcoholic liver cirrhotics have been studied. Endocrine investigations have included not only measurement of hormone concentrations under basal conditions but also hormone responses to dynamic tests of hypothalamic-pituitary-gonadal function. 


\section{Methods}

Thirty-seven male cirrhotic patients were studied. Of these, 25 were alcoholic (mean age 52.8 years, range 26.66 years) and 12 were non-alcoholic (mean age 51.8 years, range $22-74$ years); this latter group included five patients with cryptogenic cirrhosis, two patients with chronic active hepatitis and cirrhosis, one patient with chronic granulomatous liver disease, and four with haemochromatosis. The clinical diagnosis was confirmed histologically by needle biopsy of the liver in all but nine patients in whom either platelet deficiency or a prolonged prothrombin time precluded liver biopsy. Fourteen patients $(37 \%)$, including 10 alcoholics, had definite gynaecomastia which in all but two cases was bilateral. No patient had galactorrhoea.

All blood samples for basal hormone studies were taken between 9.00 and $10.00 \mathrm{am}$. The serum or plasma was then stored at $-20^{\circ} \mathrm{C}$ to await analysis at a later date. Plasma testosterone levels were measured in all patients by a specific radioimmunoassay. In 17 unselected consecutive patients (mean age 47 years; range 29-61 years) the percentage unbound testosterone was measured by steady state gel filtration (Anderson et al., 1972a; Burke, 1969). The free fraction concentration was then derived by multiplying the total testosterone level by the percentage unbound testosterone. Free testosterone levels were similarly estimated in 16 normal males (mean age 30 years, range 26-36 years).

In all patients, basal concentrations of luteinizing hormone (LH) and follicle stimulating hormone (FSH) were measured by radioimmunoassay and results were expressed in $\mathrm{mU} / \mathrm{ml}$ of $\mathrm{LH}$ and $\mathrm{FSH}$ of standard LER 907.

In 14 unselected consecutive cirrhotic males including eight alcoholics (mean age 50.8 years, range 26 to 72 years) the response of the pituitary to the gonadotrophin releasing hormone was assessed. Seven of these patients, including four alcoholics, had gynaecomastia. Basal heparinized blood samples were taken between 9.00 and 10.00 am at 0 minutes and followed immediately by a bolus intravenous injection of $100 \mu \mathrm{g}$ luteinizing hormone/follicle stimulating hormone-releasing hormone (LH/FSHRH). Further samples of blood were then taken at +20 and +60 minutes (Besser et al., 1972). All plasma samples were separated immediately and stored at $-20^{\circ} \mathrm{C}$ to await estimation of $\mathrm{LH}$ and FSH by radioimmunoassay.

In eight consecutive cirrhotic males including four alcoholics (mean age 50.8 years; range 26-72 years) the ability of the Leydig cells of the testis to respond to human chorionic gonadotrophin (HCG) was assessed by the method of Anderson et al. (Anderson et al., 1972b). Basal blood samples were taken on day 0 between 9.00 and $10.00 \mathrm{am}$. HCG (2000 IU) was then given by intramuscular injection on day 0 and on day 3 and daily blood samples for testosterone were taken between the same hours on days 1 to 5 .

\section{Results}

The free testosterone concentrations in normal subjects and cirrhotic patients are shown in Fig. 1. Regardless of aetiology and irrespective of the presence or absence of gynaecomastia, the cirrhotic patients had free testosterone concentrations $(34 \cdot 3$ $\pm 36.7 \mathrm{pg} / \mathrm{ml}$ ) (mean $\pm 1 \mathrm{SD}$ ) which were significantly lower $(P<0.001)$ than those found in the normal controls $(106.5 \pm 45 \cdot 7 \mathrm{pg} / \mathrm{ml})$. Apart from a single alcoholic patient, there was no overlap between the cirrhotics and the control patients. In contrast, total plasma testosterone concentration (not illustrated) was $5.4 \pm 1.4 \mathrm{ng} / \mathrm{ml}$ for normal subjects and $5.0 \pm 3.8 \mathrm{ng} / \mathrm{ml}$ for cirrhotics. Total plasma testosterone concentration in cirrhotics without gynaecomastia was $4.9 \pm 4.2 \mathrm{ng} / \mathrm{ml}$, and in those with gynaecomastia it was $5.6 \pm 3.4 \mathrm{ng} / \mathrm{ml}$. There were no differences between any of these groups.

The basal gonadotrophin levels are indicated in Figs. 2 and 3. The normal range for basal LH is 0.8 to $13.3 \mathrm{mU} / \mathrm{ml}$ and for basal FSH is 0.2 to 8.3 $\mathrm{mU} / \mathrm{ml}$. Irrespective of aetiology or the presence or absence of gynaecomastia all but two patients had

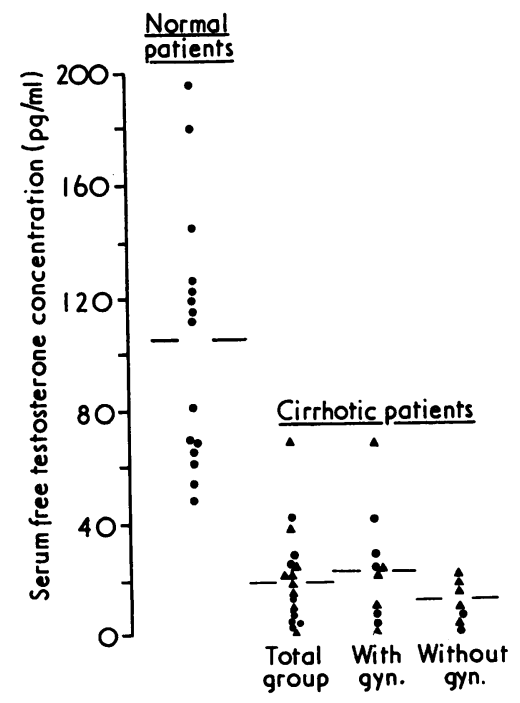

Fig. 1 Free testosterone concentrations in normal subjects and in alcoholic ( $\mathbf{\Delta})$ and non-alcoholic (O) cirrhotic male patients with and without gynaecomastia. 


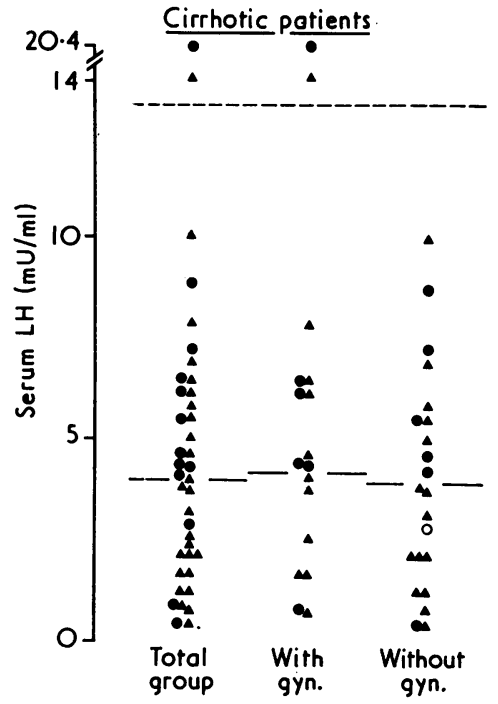

Fig. 2 Basal LH concentrations in alcoholic $(\Delta)$ and non-alcoholic (O) cirrhotic male patients with and without gynaecomastia. Dotted line indicates upper range of normal.

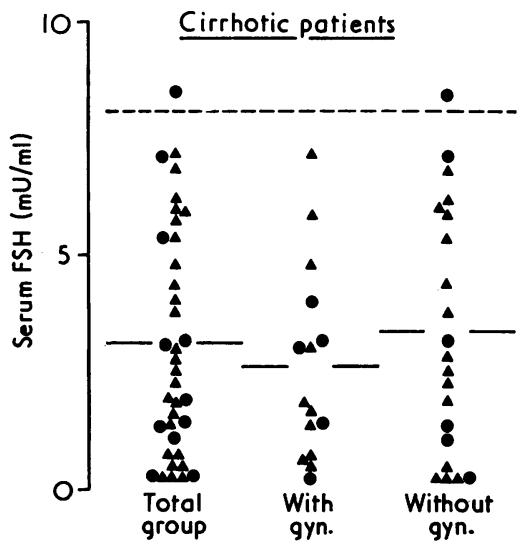

Fig. 3 Basal FSH concentrations in alcoholic (A) and non-alcoholic $(\Theta)$ cirrhotic male patients with and without gynaecomastia. Dotted line indicates upper range of normal.

normal basal $\mathrm{LH}$ concentrations $(4 \cdot 0 \pm 2 \cdot 5 \mathrm{mU} / \mathrm{ml})$ and all but two different patients had normal basal FSH concentrations $(3.1 \pm 2.4 \mathrm{mU} / \mathrm{ml})$.

All seven cirrhotic patients without gynaecomastia gave a normal LH response to LH/FSH-RH (Fig. 4). The LH response to LH/FSH-RH in the seven cirrhotics with gynaecomastia is shown in Fig. 5. Three patients (two alcoholics) gave a normal response, while four (three alcoholics) gave an exaggerated response. Two of these latter patients had slightly elevated basal LH levels. These were the only patients in the whole series with elevated basal LH concentrations.

The FSH response to LH/FSH-RH in the seven cirrhotic patients who did not have gynaecomastia is shown in Fig. 6. At 20 minutes one value from an alcoholic patient was slightly above the normal

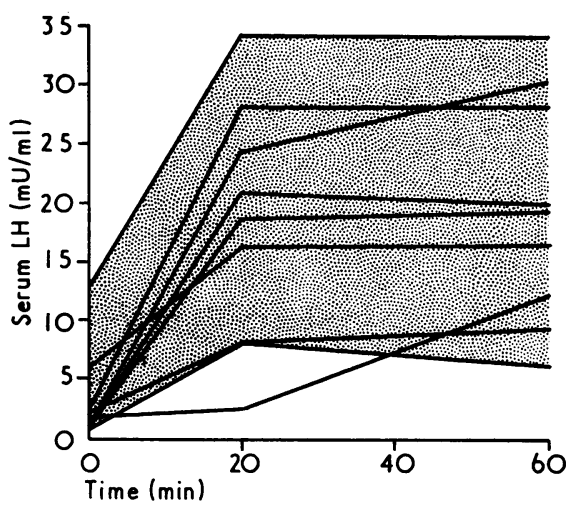

Fig. $4 L H$ response to $L H / F S H-R H$ in seven cirrhotic male patients without gynaecomastia. Hatched area represents range of normal response.

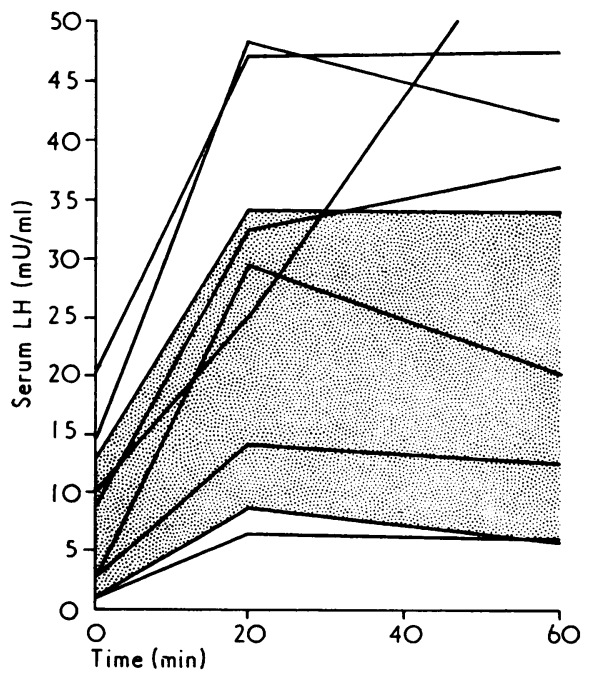

Fig. $5 L H$ response to $L H / F S H-R H$ in seven cirrhotic male patients with gynaecomastia. Hatched area represents range of normal response. 
range, while at 60 minutes four patients (two alcoholics) gave mildly exaggerated responses. These findings contrasted strongly with those in the seven cirrhotic patients who did have clinical gynaecomastia (Fig. 7). Six of these gave a markedly exaggerated FSH response to the releasing hormone, while a single alcoholic patient gave a normal response.

Sixty per cent of patients were asked to produce a specimen for sperm counting. Of these, $20 \%$ were successful. Of the seven samples obtained from cirrhotic patients, two were normal, while five were oligo- or azoospermic. The ability to produce a sample and the sperm count found were quite unrelated to either the aetiology of the liver disease or the presence or absence of gynaecomastia.

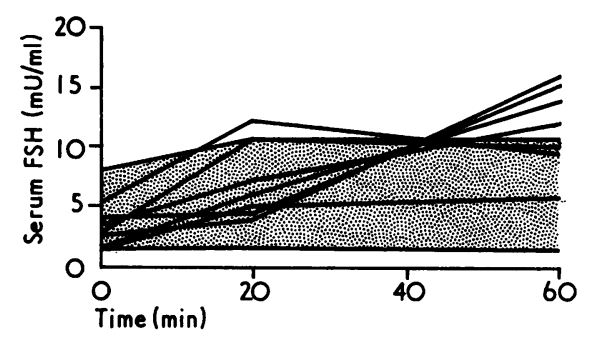

Fig. 6 FSH response to $\mathrm{LH} / \mathrm{FSH}-\mathrm{RH}$ in seven cirrhotic male patients without gynaecomastia. Hatched area represents range of normal response.

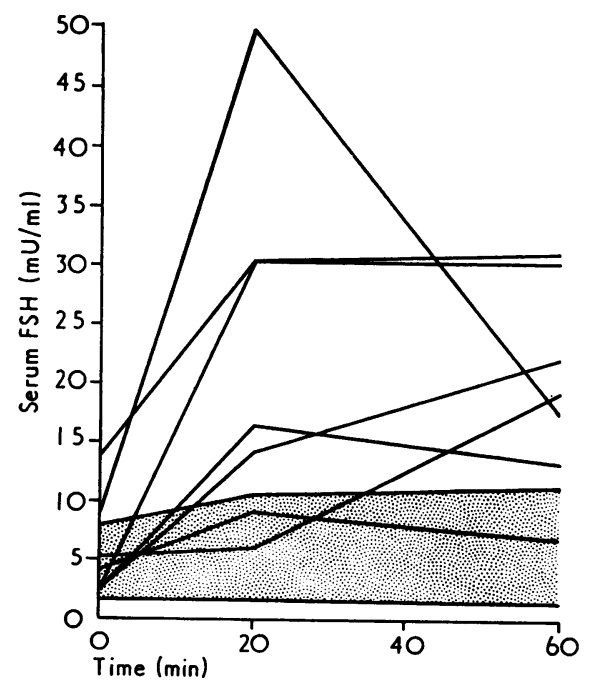

Fig. 7 FSH response to $\mathrm{LH} / \mathrm{FSH}-\mathrm{RH}$ in seven cirrhotic male patients without gynaecomastia. Hatched area represents range of normal response.

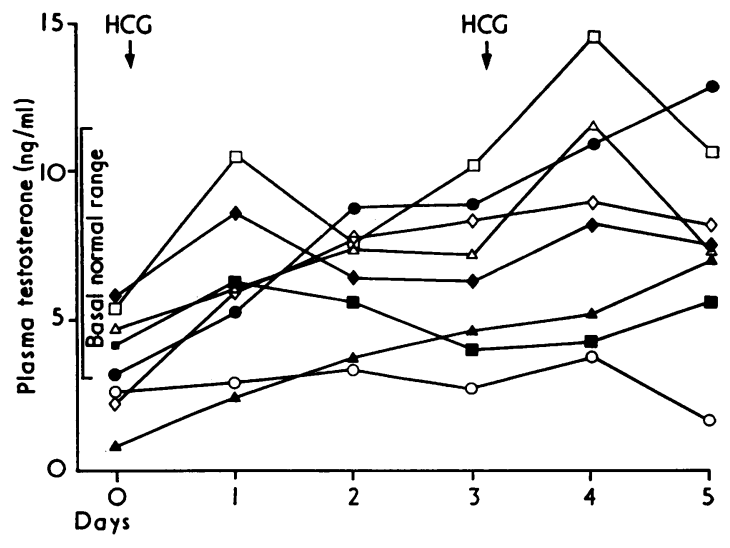

Fig. 8 Testosterone concentration after HCG administration in eight cirrhotic male patients.

The plasma testosterone rose after HCG administration in all of the eight cirrhotic patients studied (Fig. 8). A normal plasma testosterone response to HCG is defined as a rise of at least $50 \%$ above the basal level by day 3 . Using this criterion, all but one patient showed a normal response.

\section{Discussion}

Several reports have shown elevated levels of SHBG in patients with chronic liver disease (GalvãoTeles, et al., 1973; van Thiel and Lester, 1974) and we have recently shown this to be true irrespective of the aetiology of liver cirrhosis (Mowat and Dawson, in preparation). Normally, more than $98 \%$ of circulating testosterone is bound to SHBG and there is now good evidence that it is the small unbound fraction which is biologically active (MauvaisJarvis et al., 1971; Ruder et al., 1971; Burke and Anderson, 1972; Vermeulen et :l., 1972b).

Although several authors have reported normal or low circulating total androgen concentrations in cirrhosis of the liver, the results may underestimate the degree of gonadal dysfunction in patients with elevated SHBG levels Few authors have examined free testosterone concentrations. Our measurements of the free fraction show strikingly low concentrations of free testosterone irrespective of the type of cirrhosis and regardless of the presence or absence of gynaecomastia. While the marked difference between the cirrhotic groups and our control group might be partly attributable to the younger age of the controls, this is unlikely to be of significance, since it has been recently demonstrated that free testosterone levels, although tending to fall after the age of 50 years, are not significantly reduced 
until the seventh decade or later (Stearns et al., 1974). The low free testosterone concentrations that we report agree with the low free $17 \beta$-hydroxyandrogens found in cirrhotic patients by GalvãoTeles et al. (1973) and the findings of Chopra et al. (1973) on a smaller series.

The difficulty in collection of seminal fluid samples from cirrhotic male patients is well known and our experience of only a $20 \%$ successful ejaculation rate conforms with the experience of others (van Thiel et al., 1974). Five of the seven samples were oligospermic or azoospermic with only two normal ejaculates.

Thus, in the patients studied, there is evidence of both inadequate testosterone production by the Leydig cells and also inadequate sperm production by the tubular cells. This combined defect could theoretically be due to either a primary gonadal failure or else due to inadequate trophic stimulation by the hypothalamic-pituitary system.

In the presence of normal basal FSH and LH levels, low testosterone and severely impaired spermatogenesis are suggestive of both a gonadal defect and abnormal hypothalamic-pituitary function. We have demonstrated that the Leydig cells in all but one patient (Fig. 8) can respond to large doses of HCG by increasing the circulating testosterone levels by at least $50 \%$ by day 3 . This is the conventional criterion of a normal response (Anderson $e t$ $a l ., 1972 \mathrm{~b})$. However, in patients with low basal testosterone levels this may not be valid. For example, patients with panhypopituitarism with similar low levels showed an $800 \%$ rise and even patients with Klinefelter's syndrome, with high basal gonadotrophin levels, had a greater than $200 \%$ increment in plasma androgen levels (Anderson et $a l .$, 1972b). Our results therefore do not exclude a gonadal defect in testosterone production. Van Thiel et al. (1974) reported that $46 \%$ of their patients given HCG failed to achieve the $50 \%$ increment in testosterone above basal concentrations. However, $80 \%$ of the patients whom they studied had an alcoholic hepatitis, whereas none of our patients tested had this pathology.

If, however, gonadal failure is the sole cause of the abnormal spermatogenesis and reduced plasma testosterone concentrations, one would expect a compensatory increase in trophic stimulation by negative feedback via an intact hypothalamicpituitary-gonadal axis and thus elevated basal FSH and $\mathrm{LH}$ levels. The nature of the gonadal products responsible for this feedback regulation of gonadotrophin secretion in the male is not established. There is good evidence, however, that LH secretion normally correlates inversely with circulating free testosterone concentrations (Stearns et al., 1974) and that FSH secretion by the pituitary usually increases with diminished spermatogenesis, since it appears likely that some products of the germinal epithelium of the tubules play a role in inhibiting FSH secretion (Odell and Moyer, 1971; Leonard et al., 1972). Thus, in our patients the combination of normal basal plasma gonadotrophins and demonstrable gonadal hypofunction must indicate a defect in this regulatory mechanism. The defect must be located either at the hypothalamic or pituitary level and the LH/FSH-RH studies were performed in order to determine the likely site of this lesion, by testing the pituitary's ability to respond to a specific trophic stimulus.

The results of the releasing hormone studies reveal that pituitary release of LH and FSH in all patients studied is not imparred. This would indicate that the defect in the regulatory mechanism may lie in the hypothalamus. One is tempted to speculate that one cause for the hypothalamic dysfunction may be inhibition by excess circulating oestrogens in these patients; reports to date on circulating plasma oestradiol concentrations in male cirrhotic patients are contradictory and further investigation of this is required.

An interesting finding of uncertain significance in the releasing hormone studies was the marked FSH (and, to a lesser extent, LH) hyper-responsiveness seen in those cirrhotic patients with gynaecomastia; this contrasted with the largely normal FSH and LH responses seen in those patients without gynaecomastia. However, the failure of the testes of our patients to produce testosterone and sperm was equivalent irrespective of the presence or absence of gynaecomastia. While such hyperresponsiveness is typically seen when there is primary failure of the target organ (Mortimer et al., 1973), it is of considerable interest that exaggerated gonadotrophin responses to LH/FSH-RH have been reported recently in patients with normal liver function on chronic oestradiol therapy (Jaffe and Kaye, 1975). This is a further indication of the importance of studies on oestrogen metabolism in our patients.

We therefore conclude that there is evidence of a regulatory defect at the hypothalamic level and also a failure of the testes to respond to normal trophic hormone stimulation. The role of oestrogens in the pathogenesis of these abnormalities remains to be clarified. A comparable conclusion was reached by van Thiel et al. (1974) in their study of alcoholic liver disease. Our study however, shows that such abnormalities are also found in patients with nonalcoholic liver disease. This demonstrates clearly that alcohol is not an obligatory accompaniment of the endocrine changes of chronic liver disease. Further, clomiphene stimulation tests indicate 
either a hypothalamic or pituitary defect (van Thiel et al., 1974). Our releasing hormone studies clearly show that the pituitary can respond normally and thus suggest that there is abnormal hypothalamic function in these patients.

We are grateful to the Wellcome Research Foundation and to the North East Thames Regional Health Authority for financial support. We are also grateful to Professor J. Landon for allowing us to use the facilities of his laboratory.

\section{References}

Adlercreutz, H. (1970). Oestrogen metabolism in liver disease. Journal of Endocrinology, 46, 129-163.

Adlercreutz, H. (1974). Hepatic metabolism of estrogens in health and disease. New England Journal of Medicine, 290, 1081-1083.

Anderson, D. C., Marshall, J. C., Galvâo-Teles, A., and Corker, C. S. (1972a). Gynaecomastia and impotence associated with abnormal testosterone binding. Proceedings of the Royal Society of Medicine, 65, 787-788.

Anderson, D. C., Marshall, J. C., Young, J. L., and Russell Fraser, T. (1972b). Stimulation tests of pituitary-Leydig cell function in normal male subjects and hypogonadal men. Clinical Endocrinology, 1, 127-140.

Baker, H. W. G., Dulmanis, A., Hudson, B., Paulsen, A. C. Purcell, N., and Woinarski, S. (1972). Endocrine aspects of hepatic cirrhosis. In Abstracts: 4th International Congress of Endocrinology, Washington D.C. Abstr. no. 327. Excerpta Medica: Amsterdam.

Besser, G. M , McNeilly, A S., Anderson, D. C., Marshall, J. C., Harsoulis, P., Hall, R., Ormston, B. J., Alexander, L., and Collins, W. P. (1972). Hormonal responses to synthetic luteinizing and follicle stimulating hormonereleasing hormone in man. British Medical Journal, 3, 267-271.

Burke, C. W. (1969). Accurate measurement of steroidprotein binding by steady-state gel filtration. Biochimica et Biophysica Acta, 176, 403-413.

Burke, C. W., and Anderson, D. C. (1972). Sex-hormonebinding globulin as an oestrogen amplifier. Nature, 240, 38-40.

Cedard, L., Mosse, A., and Klotz, H. P. (1970). Les oestrogènes plasmatiques dans les gynécomasties et les hépatopathies. Annales d'Endocrinologie, 31, 453-458.

Chopra, I. J., Tulchinsky, D., and Greenaway, F. L. (1973). Estrogen-androgen imbalance in hepatic cirrhosis. Annals of Internal Medicine, 79, 198-203.

Coppage, W. S. Jr, and Cooner, A. E. (1965). Testosterone in human plasma. New England Journal of Medicine, 273, 902-907.

Corda, L. (1925). Scilla c.d. reviviscenza della mammella maschile nella cirrosi epatica. Minerva Medica, 5, 10671069.

Galvâo-Teles, A., Anderson, D. C., Burke, C. W., Marshall, J. C., Corker, C. S., Brown, R. L., and Clark, M. L. (1973). Biologically active androgens and oestradiol in men with chronic liver disease. Lancet, 1, 173-177.
Glass, S. J., Edmondson, H. A., and Soll, S. N. (1940). Sex hormone changes associated with liver disease. Endocrinology, 27, 749-752.

Jaffe, R. B., Keye, W. R. Jr (1975). Modulation of pituitary response to hypothalamic releasing factors. Journal of Steroid Biochemistory, 6, 1055-1060.

Kent, J. R., Scaramuzzi, R. J., and Lauwers, W., Parlow, A. F., Hill, M., Penardi, R., and Hilliard, J. (1973). Plasma testosterone, estradiol, and gonadotrophins in hepatic insufficiency. Gastroenterology, 64, 111-115.

Korenman, S. G., Perrin, L. E., and McCallum, T. (1969). Estradiol in human plasma; demonstration of elevated levels in gynecomastia and in cirrhosis. Journal of Clinical Investigation, 48, 45a.

Leonard, J. M., Leach, R. B., Couture, M., and Paulsen, C. A. (1972). Plasma and urinary follicle-stimulatinghormone levels in oligospermia. Journal of Clinical Endocrinology and Metabolism, 34, 209-214.

Lloyd, C. W., and Williams, R. H. (1948). Endocrine changes associated with Laennec's cirrhosis of the liver. American Journal of Medicine, 4, 315-330.

Lourens, J. (1973). Geslachtshormonen en Lebercirrhose, p. 125. Thesis: University of Utrecht.

Mauvais-Jarvis, P., Crepy, O., and Bercovici, J. P. (1971). Further studies on the pathophysiology of the testicular feminization syndrome. Journal of Clinical Endocrinology and Metabolism, 32, 568-571.

Mortimer, C. H., Besser, G. M., McNeilly, A. S., Marshall, J. C., Harsoulis, P., Tunbridge, W. M. G., Gomez-Pan, A., and Hall, R. (1973). Luteinizing hormone and follicle stimulating hormone-releasing hormone test in patients with hypothalamic-pituitary-gonadal dysfunction. British Medical Journal, 4, 73-77.

Odell, W. D., and Moyer, D. L. (1971). Physiology of Reproduction, p. 82. Mosby: St. Louis.

Ruder, H., Corval, P., Mahoudeau, J. A., Ross, G. T., and Lipsett, M. B. (1971). Effects of induced hyperthyroidism on steroid metabolism in man. Journal of Clinical Endocrinology and Metabolism, 33, 382-387.

Stearns, E. L., MacDonnell, J. A., Kaufman, B. J., Padua, R., Lucman, T. S., Winter, J. S. D., and Faiman, C. (1974). Declining testicular function with age. American Journal of Medicine, 57, 761-766.

Summerskill, W. H. J., Davidson, C. S., Dible, J. H., Mallory, G. K., Sherlock, S., Turner, M. D., and Wolfe, S. J. (1960). Cirrhosis of the liver: a study of alcoholic and nonalcoholic patients in Boston and London. New England Journal of Medicine, 262, 1-9.

van Thiel, D. H., and Lester, R. (1974). Sex and alcohol. New England Journal of Medicine, 291, 251-253.

van Thiel, D. H., Lester, R., and Sherins, R. J. (1974). Hypogonadism in alcoholic liver disease: evidence for a double defect. Gastroenterology, 67, 1188-1199.

Vermeulen, A., Mussche, M., Verdonck, L. (1972a). Testosterone and estradiol production rates and interconversion in normal males and male cirrhotics. In Abstracts: 4th International Congress of Endocrinology, Washington D.C. Abstr. no. 305. Excerpta Medica: Amsterdam.

Vermeulen, A., Rubens, R., and Verdonck, L. (1972b). Testosterone secretion and metabolism in male senescence. Journal of Clinical Endocrinology and Metabolism, 34, 730735. 